\title{
O Jornal Vassourense e a Política no Brasil do século XIX - 1885 a 1887
}

\author{
The Vassourense newspaper and Brazilian politics in the 19th century - 1885 to 1887
}

Angelo Ferreira Monteiro', Ailton Bezerra Lima²

Como citar esse artigo. Monteiro AF, Lima AB. O Jornal Vassourense e a Política no Brasil do século XIX - 1885 a 1887. Revista Mosaico. 2013 Jul./Dez.; $04 \quad$ (2): 13-17.

\begin{abstract}
Resumo
Buscamos neste estudo verificar o retorno da História Política, através da utilização de outras fontes, no nosso caso um jornal, diferentemente da História Política tradicional que se baseava em documentos oficiais. Tivemos como objetivo analisar e verificar o envolvimento da imprensa do município de Vassouras e sua relação com à política local, como também o seu envolvimento com as questões provinciais e nacionais. Assim optamos pela utilização das edições dos anos de 1885 a 1887 do periódico intitulado Vassourense. Palavras-chave: Política. Imprensa. Século XIX.
\end{abstract}

\begin{abstract}
This study aims to verify the return of the political history, through the use of other sources, in our case, a newspaper, unlike the traditional political history, which was based on official documents. Our objective was to analyze and verify the involvement of the Vassouras county press and its relation to the local politics, as well as its involvement with provincial and national issues. Thus we opted to use the 1885 to 1887 issues of the newspaper entitled Vassourense. Keywords: Politics. Press. 19th Century.
\end{abstract}

\section{O Jornal Vassourense e a Política no Brasil do século XIX - 1885 a 1887}

"História e Poder são como irmãos siameses - separá-los é
difícil; olhar para um sem perceber a presença do outro é
quase impossivel." Francisco Falcon, Historia e Poder ${ }^{1}$

O presente trabalho é composto de duas partes. Na primeira, foi realizada a discussão de textos sobre Política e Pensamento Político e na segunda, um trabalho prático, com uma pesquisa em fonte primária.

Francisco Falcon, em artigo intitulado História e Poder, discute a História Política tradicional, sua ascensão e queda e o retorno para uma História Política fora da figura do Estado.

"A promoção do Estado à condição de "objeto por excelência da produção histórica" significou à hegemonia da história política. Daí porque no século XIX, poder é sempre poder do Estado - instituições, aparelhos dirigentes; os "acontecimentos são sempre eventos políticos, pois são estes 1 Falcon, Francisco. História e Poder. IN: Cardoso, Ciro F. e Vainfas, Ronaldo (orgs.). Domínios da História. São Paulo, Editora Campus. p.61 os temas nobres e dignos da atenção dos historiadores". ${ }^{2}$

Segundo o mesmo Falcon, o historiador Foucault revolucionou a compreensão desses novos objetos, colocando em destaque a relação entre as diferentes práticas sociais e a pluralidade e onipresença não do poder, mas dos poderes. A historiografia política passou a enfocar nos anos 70, a Microfisica do Poder, na realidade as infinitas astúcias dos poderes em lugares históricos pouco conhecidos dos historiadores - família, escola, asilos, prisões, hospitais, hospícios, polícia, oficinas, fábricas etc.; em suma, no cotidiano de cada indivíduo ou grupo social. ${ }^{3}$ As novas correntes marxistas também vieram em auxílio dessa restauração do político em geral, ou da história política em particular. ${ }^{4}$

Finalmente, há que se registrar a importância dos contatos e trocas interdisciplinares, conhecido como

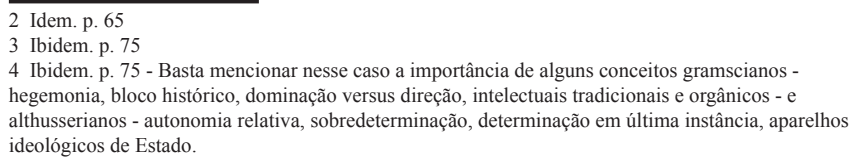
ideológicos de Estado.

2. Mestre em História pelo Programa de Mestrado em História da USS. Graduado em História pela Fundação Educacional Campograndense - FEUC. Bacharel em Direito pelo

Centro Universitário Augusto Motta - UNISUAM. Professor de Direito do C.E. Erich Walter Heine - SEEDUC. 
carro-chefes dos Annales, para esses novos rumos da história política. ${ }^{5}$

Para Hannah Arendt, o espaço passa a existir sempre que os homens se reúnem na modalidade do discurso e da ação, e portanto precede toda e qualquer constituição formal da esfera pública e as várias formas de governo, isto é, as várias formas possíveis de organização da esfera pública.(...) Onde quer que os homens se reunam, esse espaço existe potencialmente; mas só potencialmente, não necessariamente nem para sempre. (...) O que primeiro solapa e depois destrói as comunidades políticas é a perda do poder e a impotência final; e o poder não pode ser armazenado e mantido em reserva para casos de emergência, como os instrumentos da violência: só existe em sua efetivação. (...) O poder só é efetivado enquanto a palavra e o ato não se divorciam, quando as palavras não são vazias e os atos não são brutais, quando as palavras não são empregadas para velar intenções mas para revelar realidades, e os atos não são usados para violar e destruir, mas para criar relações e novas realidades. ${ }^{6}$

A segunda parte da proposta deste trabalho, foi uma pesquisa realizada no jornal Vassourense, publicado no Município de Vassouras, no século XIX, utilizou-se as edições dos anos de 1885 a 1887, buscando nessas edições, os assuntos políticos de nível regional, provincial, nacional e internacional. O Redator do jornal era o Dr. Lucindo Filho e o Gerente: João Julião Manso Sayão. Pôde-se verificar que durante o período estudado, o número de colaboradores aumentou gradativamente, demonstrando assim a boa aceitação do jornal, no ano de 1885, tinha apenas 5 colaboradores - Domingos de Almeida, Dr. Nuno Alvares, Dr. Francélio Marques, Dr. Gonçalves de Carvalho e L. M. Pecegueiro -, em 1886, passou para 10 - Dr. Domingos de Almeida, Dr. Nuno Alvares, Dr. Francelio Marques, Dr. Gonçalves de Carvalho Dr. Raymundo Corrêa, Alberto Brandão, Alberto de Oliveira, Lameira de Andrade, Jorge Pinto e Olavo Bilac - e em 1887 já contava com 17 - Dr. Domingos de Almeida, Dr. Nuno Alvares, Francelio Marques, Dr. Gonçalves de Carvalho, Dr. Raymundo Côrrea, Dr. Lucio de Mendonça, Alberto Brandão, Dr. Rodrigo Octavio, Alberto de Oliveira, Lameira de Andrade, Dr. Jorge Pinto, Olavo Bilac, Dr. Augusto de Lima, Domiciano Pinto, Dr. Avellar Fernandes, Dr. Valentim Magalhães e Alfredo Pujol. Declaravase como um periódico imparcial, noticioso e literário, publicava-se aos domingos, com uma assinatura anual

\footnotetext{
5 Ibidem. p. 76 - Se, para alguns, como Chartier, o problema maior vem a ser o de uma história cultural ancorada em uma sociologia histórica da cultura, para outros a questão-chave é mesmo a de cultural ancorada em uma sociologia histórica da cultura, para outros a questão-chave é mesmo a
uma sociologia histórica do poder, e da política. Ao mesmo tempo, a Antropologia passou a atrair cada vez mais a atenção dos historiadores, quer como antropologia cultural e antropologia política, quer como etno-história. Novas possibilidades teóricas se ofereceram aos historiadores do poder e da política a partir dos trabalhos de Geertz (1973), Sahlins (1985), L. Dumont (1966 e 1977), Balandier (1980), Clastres (1974) etc. Poder e política passam assim ao domínio da representações sociais e de suas conexões com as práticas sociais; coloca-se como prioritária a problemática do simbólico - simbolismo, formas simbólicas, mas sobretudo o poder simbólico, como em Bourdieu. O estudo do político vai compreender a partir daí não mais apenas a política em seu sentido tradicional mas,

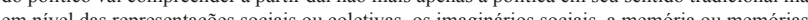
coletivas, as me

6 Arendt, Hannah. A Condição Humana. Rio de Janeiro, Forense, 2001. p. 212
}

de 10\$000 réis, que deveriam ser pagas ao Gerente Portella \& Cia. na Rua da Quitanda, $n^{\circ} 84$ B na Corte (a partir de 1887), cobrando por linha em seus anúncios $\$ 100$ réis, e quando se repetia por mais de três vezes pelo preço que se convencionasse, além de ser bastante taxativo em relação à não aceitação de testas de ferro. Em sua primeira página, encontramos o editorial, que se intitulava Semana Vassourense, onde por diversas vezes, demonstrando sua imparcialidade e preocupado com os interesses da municipalidade, o jornal exigia da Câmara Municipal a publicação das atas de reunião, que infringindo a lei, durante um ano, deixaram de ser publicadas, com isso

O sr. Pres. da Camara incumbiu-se, segundo fomos informados, de mandar fazer essas publicações no Jornal do Commercio, á sua custa, mesmo porque não queria que fossem feitas no Vassourense, não só por ser este periódico revolucionario (sic), como porque não desejava que a municipalidade concorresse para sustentar aqui um jornal., que, em lugar de fazer todos os domingos uma ladainha em louvor da mesma, ao contrario, leva o seu atrevimento e hombridade até o ponto de censurar os seus actos. (Jornal Vassourense, 11/01/1885).

Percebe-se nesta última citação que existia uma ruptura na elite local, onde parte dela se encontrava na Câmara, com seus mandos e desmandos e a outra parte no jornal, que denunciava as atitudes arbitrárias da anterior e, com estas denúncias ainda era taxado de "periódico revolucionário", pois temiam, que a população mantivesse um jornal dessa estirpe. E, o editor deixa bem claro, que voltará ao assunto, caso o Presidente da Câmara, de forma ilegal, ignore tais solicitações.

Na página 2 da mesma edição, reclamam das condições do teatro e solicitam um projeto de construção de um novo. Na seção denominada "um pouco de tudo", um artigo intitulado Aphorismus eleitoraes, onde o texto é descrito em latim. Na seção "Folhetim" contém contos literários e diversas poesias. Nesta edição diferente das demais os anúncios iniciam na página 3 e o que nos chamou a atenção na página 4, foi um aviso de fuga de escravo, que sabia ler e escrever.

$\mathrm{Na}$ edição de 14 de junho de 1886, na seção "Noticiário", que se encontra no mesmo local do editorial, o Jornal denuncia um fato que aconteceu no dia 8 do corrente, no Tribunal do Júri, onde o seu Presidente de forma ofensiva, insultou um jurado que

na vespera tinha-se apresentado em sua casa um sr. jurado
com uma petição na qual declarava que não podia servir
esse cargo por fala absoluta de meios, e ser pauperrimo.
E o sr. presidente do tribunal nomeou o nome do jurado.
Disse mais s.s. que era uma vergonha que se alistassem
como eleitores cidadãos como esses, que viviam às sopas
dos chefes políticos e que no entanto não podião ser jurados.
Disse mais que a fatal lei da reforma eleitoral era a
causa disso, e outras cousas de igual jaez, que nos
abstemos de repetir. (Vassourense, 14/06/1886) 
O jornal reconheceu que a lei infelizmente dava atribuições demais ao presidente do tribunal do júri e disse infelizmente, pois questiona como pode exercer esse cargo, um cidadão que não tem critério para desempenhar a sua função e que, ainda se acha no direito de ofender jurados e fazendo da sessão do júri discursos sobre reforma eleitoral.

\section{E continua}

o sr. presidente do tribunal exorbitou deploravelmente, e, felizmente para s.s., escolheu para victima da sua tirada biliosa um pobre senhor que não soube ter bastante energia para responder-lhe e chamal-o a ordem, já que s.s. era o primeiro a perturbal-a, e a fazer da cadeira presidencial do jury, uma tribuna de declamação fóra de proposito. E no caso de que se trate s.s. devia por coherencia não o uzar dessas palavras. Esse jurado foi alistado como eleitor pelo sr. wjuiz de direito da comarca de Vassouras, e a prova que apresentou foi a certidão de jurado pela revisão de 1878; por conseguinte foi jurado antes de ser eleitor, e a censura não cabe aos chefes políticos que alistão como eleitores cidadãos que não podem ser jurados, mas aos juizes de direito que alistão jurados cidadãos sem os necessários requisitos. (Vassourense, 14/06/1886)

Richard Graham, em Clientelismo e Política no Brasil do século XIX, no capítulo O Teatro das Eleições, conclui que os historiadores, como os contemporâneos, deparam-se com um emaranhado de ambigüidades na definição de quem podia legalmente votar. AConstituição de 1824 estendeu o voto à "massa dos cidadãos ativos", e pelos seus termos, abrangia de longe mais pessoas que o eleitorado dos membros das câmaras municipais nos tempos coloniais - ultrapassando mesmo a prática da maioria dos países europeus de então. Para ser exato, é óbvio que se excluíam escravos e mulheres, sem mesmo mencioná-los, embora as urnas se abrissem aos homens livres e analfabetos, sem enunciar qualquer distinção baseada na raça. ${ }^{7}$

Quando uma legislação dá margem à várias interpretações, o critério utilizado para aplicá-la se adequará de acordo com os interesses daqueles que querem alcançar o poder político ou nele permanecer.

Após este fato, foi feito novo sorteio onde se marcou a sessão para o dia seguinte, onde seriam julgados os reús que praticaram crimes, sendo esta sessão novamente adiada para o dia 10 , concluindo somente no dia 11, devido a ausência de jurados.

Na edição de 20 de setembro de 1885 , na seção "Semana Vassourense", foi feita a afirmação - a matéria não é assinada - de que no mundo político existem elefantes brancos, pois devido a lei Saraiva Cotegipe, que perseguia os abolicionistas no Rio de Janeiro, os obrigou a se retirar da vida política, pois defendiam também a criação da federação, pondo em risco a centralização do poder monárquico, percebe-se também

\footnotetext{
7 Graham, Richard. Clientelismo e Política no Brasil do século XIX. Rio de Janeiro, UFRJ, 1997.
} p. 142 . que o jornal é a favor do partido liberal, pois reconhece que através da federação

vira dar vida ás provincias hoje atrophiadas pela mais
inepta e ferrenha centralisação e era o meio suave
e seguro de expurgar do governo de nossa patria a
monarchia, planta exotica e desnecessaria na America.
Oprojectodormiráabafadonosarchivos dacamarapormuitos
annos, mas ha de ser lei um dia imposta pela necessidade,
pois não é possivel que a opinião popular continue, como a
nossa, a manter-se indifferente deante da ruina das provincias
cada vez mais imminente (Vassourense, 20/09/1885).

Na matéria seguinte, o jornal demonstra o corte de parte da verba anual da Câmara dos Deputados para a Família Real, no valor total 1.170:100\$000, mas lamenta se as mesmas vierem mais avolumadas pelo Senado.

Entretanto era preciso que o dinheiro do contribuinte não continuasse a alimentar principes malandros e viajantes como até agora.

Dê-se ao chefe da família imperial o necessario para manter-se com dignidade e à farta, mas o resto faça o que eu e outros fazemos, trabalhe.

Vejão os que me lêem, o que por ahi vai:
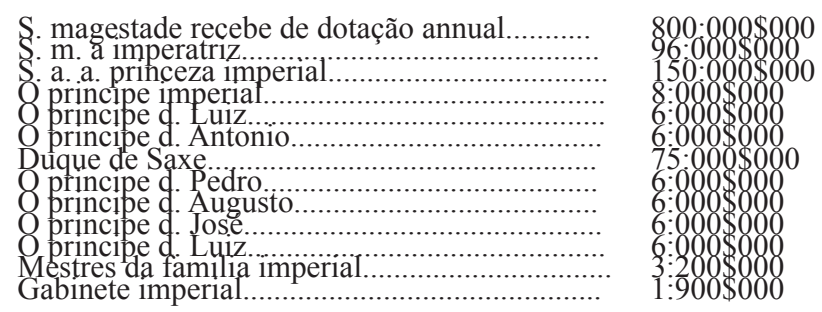

Na página 2 desta edição, encontramos na seção Folhetim, um artigo intitulado "Escriptores Acadêmicos" de autoria de Jorge Pinto - neto de Domiciano Leite Ribeiro, Visconde de Araxá -, sobre os estudante de Medicina e Ciências Jurídicas. Na página 3: Literatura, Seção Livre, Avisos da Santa Casa de Misericórdia, Ao público, Agradecimentos, Questão forense (sentença de processo). Na página 4: Editais, declaração da Santa Casa de Misericórdia. Anúncios: do Club Athletico Vassourense, do Elixir Depurativo de Manso Sayão; Serviços de Advocacia, Aviso sobre inventários, Serviços de Jardineiro e sobre a Herva Homeriana para Tísica pulmonar.

Em sua primeira edição do ano de 1886, em 3 de janeiro, o jornal completa cinco anos de existência, apesar de lamentar a falta de apoio da população e da própria imprensa em fornecer matérias para publicação.

$\mathrm{Na}$ edição de 18 de abril do corrente ano, a reclamação é em relação a situação da água no município.

Em sua edição de 23 de maio do corrente ano, Alberto Brandão, direciona a matéria para o Clube de Lavoura de Vassouras, onde discute o fim da escravidão e o esgotamento do solo. Reconhece que estas duas causas em muito contribuirá para o declínio da produção 
nos estabelecimentos agrícolas da Província do Rio de Janeiro, sabendo que

A primeira não pôde ser combatida: a escravidão tem seus dias contados e para substituil-a vantajosamente o lavrador actual pouco deve esperar dos libertos e cousa alguma da colonisação estrangeira. Nenhum povo da Europa, nem mesmo o portuguez, está apto para o trabalho das fazendas de café, como estas se achão constituidas, e, quando estivesse, nova difficuldade se levantaria - a do salario.

\section{Para isso, como diz Alberto Brandão,}

O recurso salvador, a introducção dos coolies, como meio de transição, foi anullado pela rethorica fôfa de meia dúzia de declamadores e sentimentalistas de barriga cheia todas as razões levantadas contra a immigração chineza, note-se, já existião quando ella foi largamente admittidas nos Estados-Unidos, onde prestou immensos serviços. A propaganda contra appareceo só quando as classes operarias já numerosas virão nos coolies concurrentes invenciveis pela aptidão e pela modicidade do salario. O que lá pois influio para que elles fossem condemnados era motivo de aceitação entre nós, que carecemos de trabalhadores em grande numero e a preço baixo.

O primeiro encontro da delegação chinesa com o Imperador D. Pedro II, quanto à proposta da transição do trabalho escravo africano para o livre, com a inserção dos coolies se deu em 13 de outubro de 1883, e por ser sábado, o beija-mão era aberto ao público, tendo neste dia um total de 20 pessoas - que assinaram o livro de registros. ${ }^{8}$ Após três anos de discussão o assunto ainda estava em voga, como vimos na edição de 1886 do jornal Vassourense. Sendo esta proposta, para os barões de café, a salvação para o trabalho nas lavouras.

A outra causa levantada pelo jornal na mesma matéria é o esgotamento do solo, onde reconhecem o problema, causado pelo

o desapparecimento das mattas (que) é quasi geral na

8 Silva, Eduardo. Dom Obá II D’África - O Príncipe do Povo. São Paulo, Companhia das Letras, 1997. p. $96-97$ e 102. Como de costume, os viajantes começam a chegar ao cair da tarde, pouco antes das seis horas. Entram pela porta principal, utilizada apenas por ministros e servidores mais graduados, e tomam os seus lugares. Um ou outro pode ter-se demorado, se a luz do dia o permitisse, na observação dos quadros expostos na galeria que leva até a sala de audiência. Ainda uma vez, o primeiro cavalheiro a ssin o livro de visita foi Dom Obá I d' Á frica - representante dos “pardo ph e " que vivis á e pres" que vivio a a do sisten, em ativida para baixo, como convém a um poderoso príncipe; avança sem olhar para os lados até à primeira fila, onde está seu lugar ao lado do major Morim. Com sorriso superior observa entre os demais, saúde displicentemente o pessoal do serviço e espera com dignidade a chegada do imperador." Com a chegada deste, contudo, "derrete-se o seu orgulho como manteiga ao sol [...], dobra os joelhos como um miserável vassalo e, sempre de joelhos, beija a mão do imperador..." -. Ao lado do alferes, dividindo o privilégio da primeira fila, um outro militar, o major Morin. Monsieur Morin, um mercenário francês contratado ao tempo de dom Pedro I, envergava ainda, aos 86 anos, o uniforme de gola branca dos primeiros anos da Independência. A pesar da idade, também o major era figura obrigatória e lá estaria todos os sába los, cáse chuva ou batese sol.

obrigatón c lá estaria todos os sábados, caisse chuva ou balesse sol. a guerra, tenente honorário Pedro Augusto da Cunha, tenente-coronel Ferreira Lima e capitão-de-mar-e-guerra Marques Guimarães. Havia gente titulada, como o barão de Palmeiras e o conselheiro Paula Souza; intelectuais, como o pintor Vítor Maireles e o bibliográfo Sacramento Blake; e uma comissão de professores do Imperial Instituto dos Meninos Cegos.

A comissão mais numerosa e que chamou mais a atenção naquele dia foi, sem dúvida, a dos diretores da Companhia Comércio e Imigração Chinesa, que se fazia acompanhar, solenemente, do mandarim Tong Kingsing (como o nome parece no registro) e seu secretário californiano, um certo G. A. Butley. Mr. Butley eo alferes Galvão eram os ínicos pretes na sala de audiência daquele di 13. O Príncipe, Me Bundo Vo Kositz, "f es roup pretas e [] per ver. Butley, segundo a mesma fonte, como "um verdadeiro gentleman", além de "coberto de brilhantes". provincia e já se atravessão grandes extensões, em que o plantio do cafeeiro é impossivel por improductivo. E' certo que a sciencia tem processos seguros para renovação das forças das terras; mas arar montanhas, estrumar milhares e milhares de pés de café etc é de difficil execução principalmente nas grandes propriedades agricolas. Tambem qualquer medidas das aconselhadas pelos principios economicos produziria fructos sem duvida alguma, mas com tal lentidão que em nada aproveitarião aos actuaes lavradores. Estes pois achão-se em uma situação aterradores e que só será dominada se houver de sua parte muita cohesão de idéas e energia prudente para pôl-as em pratica.

Com a falta de braços na lavoura e o esgotamento do solo, outro problema enfrentado pelos lavradores da Província do Rio de Janeiro era

continuar a pagar a bancos e commissarios juros de $12 \%$. Isto é incontestavel e não carece ser illudido. Pois bem: o proprio Estado, pelo que louvamos muito o actual sr. ministro da fazenda, achou superior ás suas forças pagar $6 \%$ annuaes pelas suas apolices e reduzio a taxa a $5 \%$. Como pois ha-de o lavrador arrastar-se submettido a juros, para cuja satisfação não tem recursos?

O jornal reivindica o apoio do poder público a essa classe, dizendo que era dela, a fonte mais abundante da receita nacional, questionando se

Os seus representantes no parlamento e no governo a deixarão abandonada, entregue de pés e mãos a exigencias, que trarão infallivelmente a sua ruina? Acreditamos que não.

\section{Além disso o jornal declarava:}

Os clubs da lavoura na atualidade devem tomar a si a cruzada do abaixamento de juros e podem tudo conseguir pelos meios legaes, desde que operem unidos e energicamente. E' o que lembramos ao de Vassouras. Alberto Brandão.

Na primeira edição do ano de 1887, em 2 de janeiro, o jornal completa 6 anos de existência, citando a tarefa espinhosa que deve cumprir, onde nem sempre agrada a todos. Em 18 de janeiro, o problema da água no município, continua a ser registrado. Ainda nesta edição, o jornal Vassourense, reclama do jornal Diário de Notícias - do Rio de Janeiro - pela alteração nas suas matérias, editadas por este, vamos citar alguns exemplos, o Vassourense relatou que uma faísca elétrica caiu sobre a cas do Barão de Avellar, o Diário de Notícias, de forma sensacionalista, com a mesma matéria diz que o Barão de Avellar foi vítima de um raio, como causa o Barão recebeu muitas cartas e telegramas de amigos e parentes distantes que estavam preocupados; Um amigo do jornal de Vassouras estava muito doente, o Diário noticiou que ele estava gravemente doente; e por último, quando o Vassourense relata que foi descoberto um caso de varíola no bairro do Madruga, localidade próxima ao 
centro da cidade, o Diário descreve que Vassouras sofre com epidemia de varíola.

Em 06 de março do corrente ano, na seção Noticiário, é publicado o aviso de que no dia 30 do corrente mês as 4 horas da tarde encerra-se o prazo para a nova matrícula de escravos. Os que não forem matriculados serão considerados livres. Em uma das matérias consta os ótimos efeitos do elixir depurativo de Manso Sayão.

Em 08 de maio deste mesmo ano, o jornal inicia a publicação de um artigo francês intitulado "A Higiene das Cidades e os Orçamentos Municipais", traduzido pelo Sr. Julio Rochard, da Academia de Medicina de Paris.

Por fim, utilizamos a edição de 12 de junho do corrente ano, onde na primeira página, constava que

\begin{abstract}
Achava-se em Campinas, procedente dos Poços de Caldas, o preto Silvestre, que tem a mania das grandezas. Julga-se rei do Congo, possuidor de milhares de contos de réis e de muitos outros cabedaes, cuja enumeração tornar se-ia sobre maneira enfadonha. Comtudo, é inteiramente inoffensivo; o que nem sempre acontece com o seu illustre primo, o principe Obá II d'Africa, que quando bebe, é da pelle, como vulgarmente se diz.
\end{abstract}

Ainda na primeira página o jornal nos informa os novos jurados sorteados para a próxima sessão do júri. Em sua segunda página o jornal, na sessão Anatomia da Imprensa, comenta a atitude displicente do Diário de Notícias, que continua a comemorar o aniversário do terceiro centenário de Camões (10/06/1580), que foi em 1880. Nesta mesma página inicia os contos literários e as poesias que se encerram na página 3, nesta, encontramos a continuação do artigo francês sobre "A Higiene das Cidades e os Orçamentos Municipais", contendo ainda a Seção Livre e na página 4, os anúncios em geral, Declaração da Irmandade, Obituário, Serviços de Advogado e Remédios.

\section{Conclusão}

Verificamos no período estudado, que nas entrelinhas do jornal Vassourense, existia uma ruptura na elite de Vassouras, onde o jornal deixava muitas vezes a sua imparcialidade - declarada abaixo do título do jornal - de lado e denunciava irregularidades nos trabalhos da Câmara Municipal, excessos do presidente do Tribunal do Júri; em nível provincial, a falta de apoio do Parlamento aos lavradores, em relação aos juros altos e a transição do trabalho escravo para 0 livre e a nível nacional quando questionava o papel da Monarquia - chegando a taxá-la de planta exótica na América - pois não viam mais qual era a sua função para a nação. Para isso, utilizamos o artigo de Francisco Falcon, onde este autor conclui o retorno da História Política, com a utilização de outras fontes para a sua realização, através da apreensão dos discursos ou fontes de época, como foi no nosso caso, optamos pelo jornal, para demonstrarmos como era o exercício da política no século XIX. Diferente da História Política Tradicional, que se baseava apenas na utilização de documentos oficiais. Com Hannah Arendt, também verificamos as relações de poder da imprensa, com a propagação de suas idéias e denúncias na política da cidade, província e do império.

\section{Referências}

Arendt, Hannah. A Condição Humana. Rio de Janeiro, Forense, 2001. p. 212.

Falcon, Francisco. História e Poder. IN: Cardoso, Ciro F. e Vainfas, Ronaldo (orgs.). Domínios da História. São Paulo: Editora Campus, 1997. p.61.

Grahan, Richard. Clientelismo e Política no Brasil do século XIX. Rio de Janeiro, UFRJ, 1997.

Silva, Eduardo. Dom Obá II D’África - O Príncipe do Povo. São Paulo, Companhia das Letras, 1997. 